Note: This is a preprint of a paper being submitted for publication. Contents of this paper should not be quoted nor referred to without permission of the author(s).

EPITAXIAL GROWTH OF OXIDE THIN FILMS ON (001) METAL SURFACES USING PULSED-LASER DEPOSITION

D. P. NORTON, C. PARK, B. SAFFIAN, J. D. BUDAI, A. GOYAL,

D. K. CHRISTEN, D. M. KROEGER, D. LEE, Q. HE, AND M. PARANTHAMAN

Submitted to the Spring MRS Meeting

San Francisco, CA March 1997

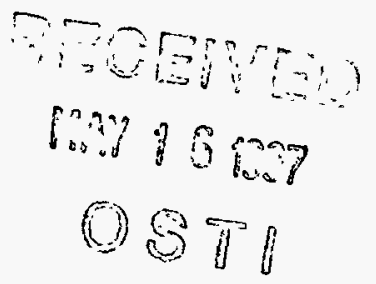

"The submitted manuscript has been authored by a contractor of the U.S. Government under by a contractor of the U.S. Government under contract DE-AC05-960R22464. Accordingly, royalty-free license to publish or reproduce the published form of this contribution, or allow others to do so, for U.S. Government purposes."

Prepared by

Solid State Division

Oak Ridge National Laboratory

P.O. Box 2008

Oak Ridge, Tennessee 37831-6056

managed by

LOCKHEED MARTIN ENERGY RESEARCH CORP.

for the

U.S. DEPARTMENT OF ENERGY

under contract DE-AC05-96OR22464 


\section{DISCLAIMER}

This report was prepared as an account of work sponsored by an agency of the United States Government. Neither the United States Government nor any agency thereof, nor any of their employees, make any warranty, express or implied, or assumes any legal liability or responsibility for the accuracy, completeness, or usefulness of any information, apparatus, product, or process disclosed, or represents that its use would not infringe privately owned rights. Reference herein to any specific commercial product, process, or service by trade name, trademark, manufacturer, or otherwise does not necessarily constitute or imply its endorsement, recommendation, or favoring by the United States Government or any agency thereof. The views and opinions of authors expressed herein do not necessarily state or reflect those of the United States Government or any agency thereof. 


\section{DISCLAIMER}

Portions of this document may be illegible in electronic image products. Images are produced from the best available original document. 


\title{
EPITAXIAL GROWTH OF OXIDE THIN FILMS ON (001) METAL SURFACES USING PULSED-LASER DEPOSITION
}

\author{
D. P. NORTON, C. PARK, B. SAFFIAN, J. D. BUDAI, A. GOYAL, D. K. \\ CHRISTEN, D. M. KROEGER, D. LEE, Q. HE, AND M. PARANTHAMAN \\ Oak Ridge National Laboratory, Oak Ridge, TN 37831-6056
}

\begin{abstract}
The epitaxial growth of $\mathrm{CeO}_{2}$ on various (001) metal surfaces using pulsed-laser deposition is discussed. In particular, the growth of (001) $\mathrm{CeO}_{2}$ on (001) $\mathrm{Pd}, \mathrm{Ag}$, and $\mathrm{Ni}$ is described. Emphasis is given to the specific deposition conditions which successfully alleviate the formation of native oxides at the metal/metal oxide interface. The control of the epitaxial relationships between the oriented oxides films and the underlying noble and oxidizing metal surfaces is addressed. In addition, recent use of these heterostructures in the epitaxial growth of high temperature superconducting films on biaxially-textured metal substrates for superconducting wire development is described.
\end{abstract}

\section{INTRODUCTION}

The growth of epitaxial metal oxide/metal thin-film heterostructures is important for many applications involving superconducting and ferroelectric oxide materials. For example, recent efforts to utilize thermo-mechanically processed metal tapes as substrates for long-length cuprate superconductors has defined a viable route for producing highcurrent superconducting wires for operation at $77 \mathrm{~K}$.[1] In addition, many ferroelectric device structures have a metal / oxide interface at the electrode/ferroelectric boundary. The metal / oxide interfaces created in these structures often present special challenges involving chemical reactivity, lattice mismatch, and thermal expansion mismatch. In addition, the formation of native oxides on the metal surface prioir to or during deposition represents a significant obstacle to achieving epitaxial growth. The utilization of these structures will require the development of deposition techniques that can circumvent these difficulties, as well as an understanding of these interfaces, both during epitaxy and after formation.

In this paper, we describe the epitaxial growth and properties of ceria on (001) $\mathrm{Ag}, \mathrm{Pd}$, and Ni surfaces using pulsed-laser deposition. These materials are often utilized as buffer layers in high-temperature superconducting film applications, and possess structural and chemical properties that are similar to many ferroelectric oxides. The epitaxial relationships between the oriented $\mathrm{CeO}_{2}$ oxides films and the underlying noble and oxidizing metal surfaces is addressed. 


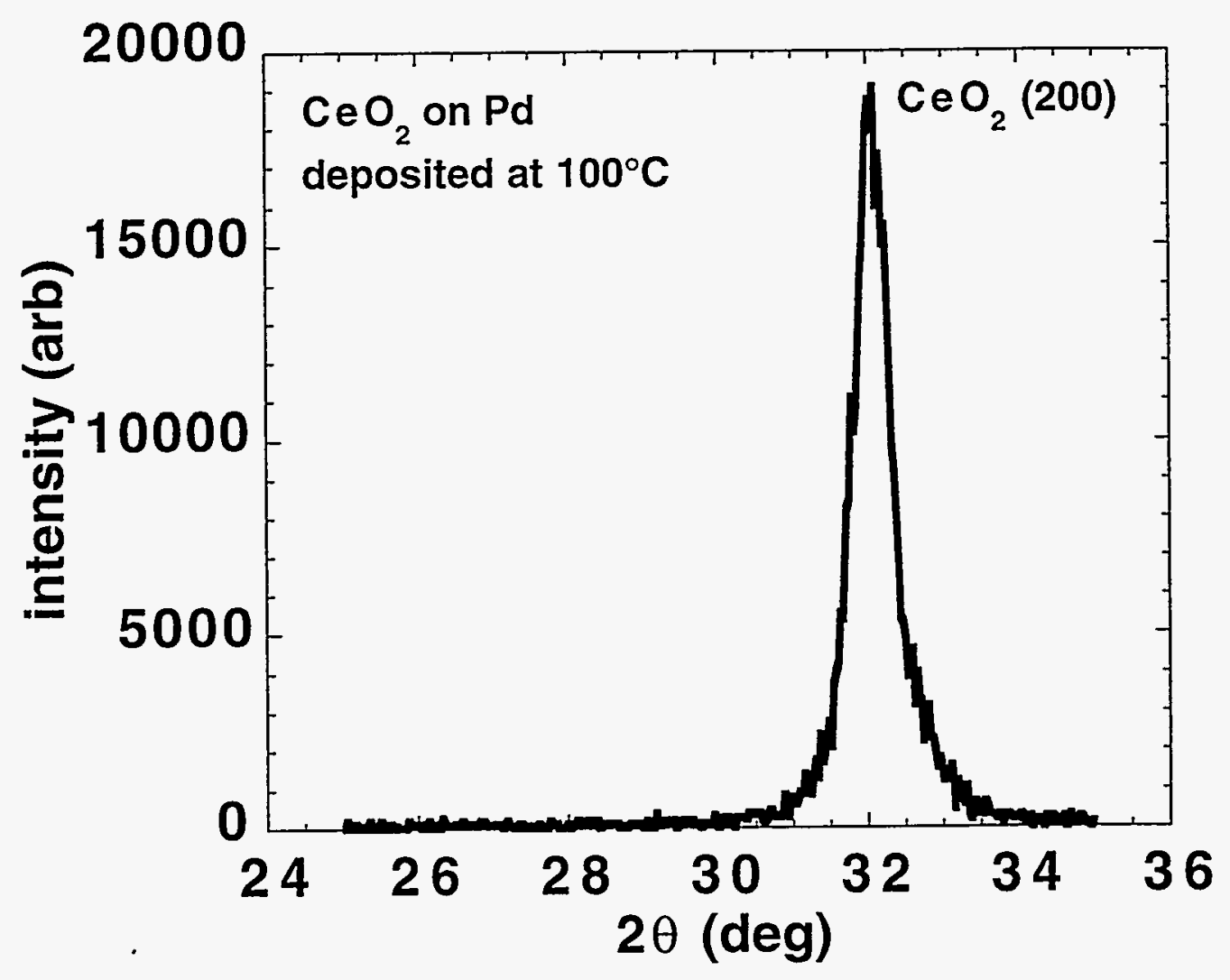

Fig. 1. X-ray diffraction pattern for a $\mathrm{CeO}_{2}$ film deposited on (001) $\mathrm{Pd}$ at $100^{\circ} \mathrm{C}$.

\section{EXPERIMENT}

The $\mathrm{CeO}_{2}$ films were deposited in a multi-target pulsed-laser deposition system. The base pressure of the vacuum system was $\sim 4 \times 10^{-6}$ Torr. Stoichiometric polycrystalline oxide disks were used as the ablation targets. A KrF $(248 \mathrm{~nm})$ excimer laser was used as the ablation source with a laser energy density of $\sim 4 \mathrm{~J} / \mathrm{cm}^{2}$. The laser repetition rate was $3.3 \mathrm{~Hz}$, with a deposition thickness per laser shot of $\sim 0.5 \AA$. Typically, the final $\mathrm{CeO}_{2}$ film thickness was $\sim 500 \mathrm{~nm}$, although some multilayer structures consisted of much thinner individual layer thicknesses. The substrates used in this study were biaxially-textured (001) Ni tapes, formed by cold-rolling and annealing pure Ni.[1] The resulting in-plane and out-of-plane crystallographic alignment was FWHM $\sim 8^{\circ}$ as determined by four-circle $\mathrm{x}$-ray diffraction. The surfaces of the as-rolled and annealed Ni substrates were quite smooth due to the use of highly polished rollers, and required no additional polishing. For the epitaxial growth of oxides on (001) noble - metal surfaces, an epitaxial layers of either $\mathrm{Pd}$ and $\mathrm{Ag}$ was sputter- or electron-beam deposited onto the (001) Ni surface. 


\section{EPITAXIAL $\mathrm{CeO}_{2}$ ON NOQBLE METALS}

The epitaxial growth of oxides on noble metals is the simplest case to consider, as there are no stable native oxides on the surface to interfere with epitaxy. For the growth of $\mathrm{CeO}_{2}$ on Pd and $\mathrm{Ag}$ using PLD, the range of deposition conditions in which (001) oxide epitaxy is realized differs for the two substrate materials. For the case of (001) Pd, epitaxial growth of $(001) \mathrm{CeO}_{2}$ is observed at substrate temperatures ranging from room temperature up to $300^{\circ} \mathrm{C}$, with the best results obtained at $100^{\circ} \mathrm{C}$. Figure 1 shows the $x$-ray diffraction $2 \theta$-scan of a $\mathrm{CeO}_{2}$ film grown on a (001) Pd surface at a substrate temperature of $100^{\circ} \mathrm{C}$. The film was in-plane aligned with the $\mathrm{CeO}_{2}$ [100] axes rotated $45^{\circ}$ with respect to the $\mathrm{Pd}[100]$. For consistent (001)-oriented $\mathrm{CeO}_{2}$ film growth at low temperature, the initial $100 \AA$ was deposited in vacuum ( $\mathrm{P}_{\text {background }}<5 \times 10^{-6}$ Torr), with the remaining majority of the film deposited in an oxygen pressure of $\sim 4 \times 10^{-4}$ Torr. In witu at $500^{\circ} \mathrm{C}$ yielded similar results without the initial vacuum deposition.

We have also investigated the growth of $(001) \mathrm{CeO}_{2}$ on (100) $\mathrm{Ag}$. Unlike the case with $\mathrm{Pd}$, the growth of (001) $\mathrm{CeO}_{2}$ on (001) Ag required a deposition temperature of at least $600{ }^{\circ} \mathrm{C}$ in order to achieve good epitaxy. X-ray diffraction scans for $\mathrm{CeO}_{2}$ films grown at $600-750^{\circ} \mathrm{C}$, show only the $(001)$ orientation. Although not shown, scanning electron microscopy images of $\mathrm{CeO}_{2}$ films grown on $\mathrm{Ag}$ at elevated temperature show only partial surface coverage, presumably an effect stemming from the high vapor pressure of the substrate. As with $\mathrm{Pd}$, the $\mathrm{CeO}_{2}$ film on $\mathrm{Ag}$ was in-plane aligned with the $\mathrm{CeO}_{2}(100)$ axes rotated $45^{\circ}$ with respect to the $\mathrm{Ag}(001)$. Previous work reported similar results for the epitaxial growth of $\mathrm{YBa}_{2} \mathrm{Cu}_{3} \mathrm{O}_{7}$ directly on single crystal Ag.[2]

\section{EPITAXIAL OXIDE ON (001) Ni}

The epitaxial growth of an oxide on the surface of an oxidizing metal is significantly complicated by the crystal structure and orientation of the native oxide. For example, the oxidation of a (001) Ni surface typically results in the formation of (111)-oriented NiO.[3]. Subsequent growth of another oxide results in a similar (111) orientation. Obviously, it is imperative that the native oxide be removed prior to epitaxial growth. For some metals, such as $\mathrm{Ni}$, an effective approach for the removal of the native oxide achieving this is to heat the metal in the presence of hydrogen gas. This results in the reduction of the $\mathrm{NiO}$, and enables the formation of a (001)-oriented epitaxial oxide on the (001) Ni surface. Fig. 2 shows $\mathrm{x}$-ray diffraction 0-20 scans for $\mathrm{CeO}_{2}$ films grown on (001) Ni substrates in which a $4 \% \mathrm{H}_{2} / \mathrm{Ar}$ mixture was introduced as a background gas during the pulsed-laser deposition. The Ni substrates were annealed at $900^{\circ} \mathrm{C}$ in a $4 \%$ $\mathrm{H}_{2} / \mathrm{A} r$ gas mixture prior to film growth to reduce any NiO initially on the substrate surface. Deposition was carried out at a substrate temperature of $750^{\circ} \mathrm{C}$. Consistent (001)-oriented epitaxial growth of $\mathrm{CeO}_{2}$ was achieved only if the oxide growth was initiated in the presence of the $\mathrm{H}_{2} /$ Ar mixture. This clearly shows that the nucleation of 


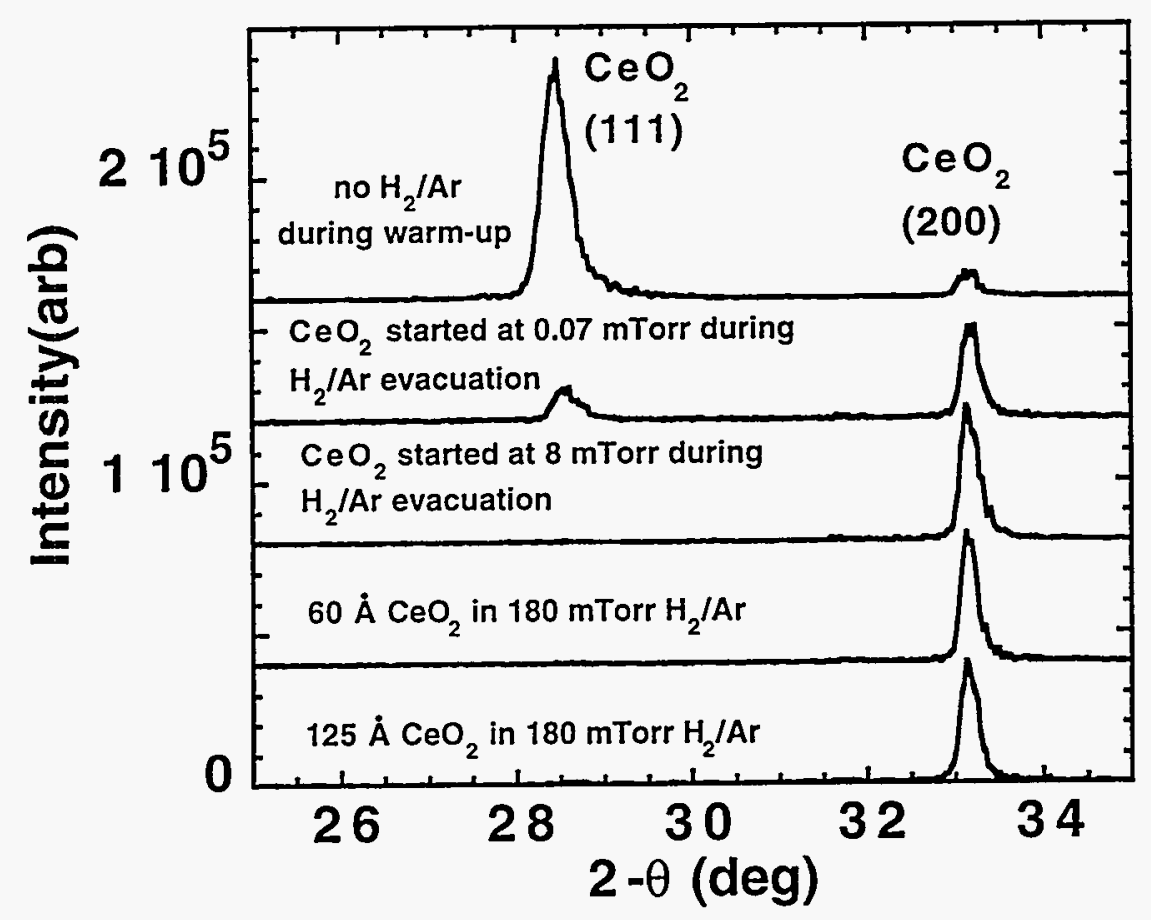

Fig. 2. X-ray diffraction patterns for $\mathrm{CeO}_{2}$ films grown on (001) Ni with and without a $4 \% \mathrm{H}_{2} / \mathrm{Ar}$ background gas during the initial nucleation of the film. Growth temperature was $750^{\circ} \mathrm{C}$.

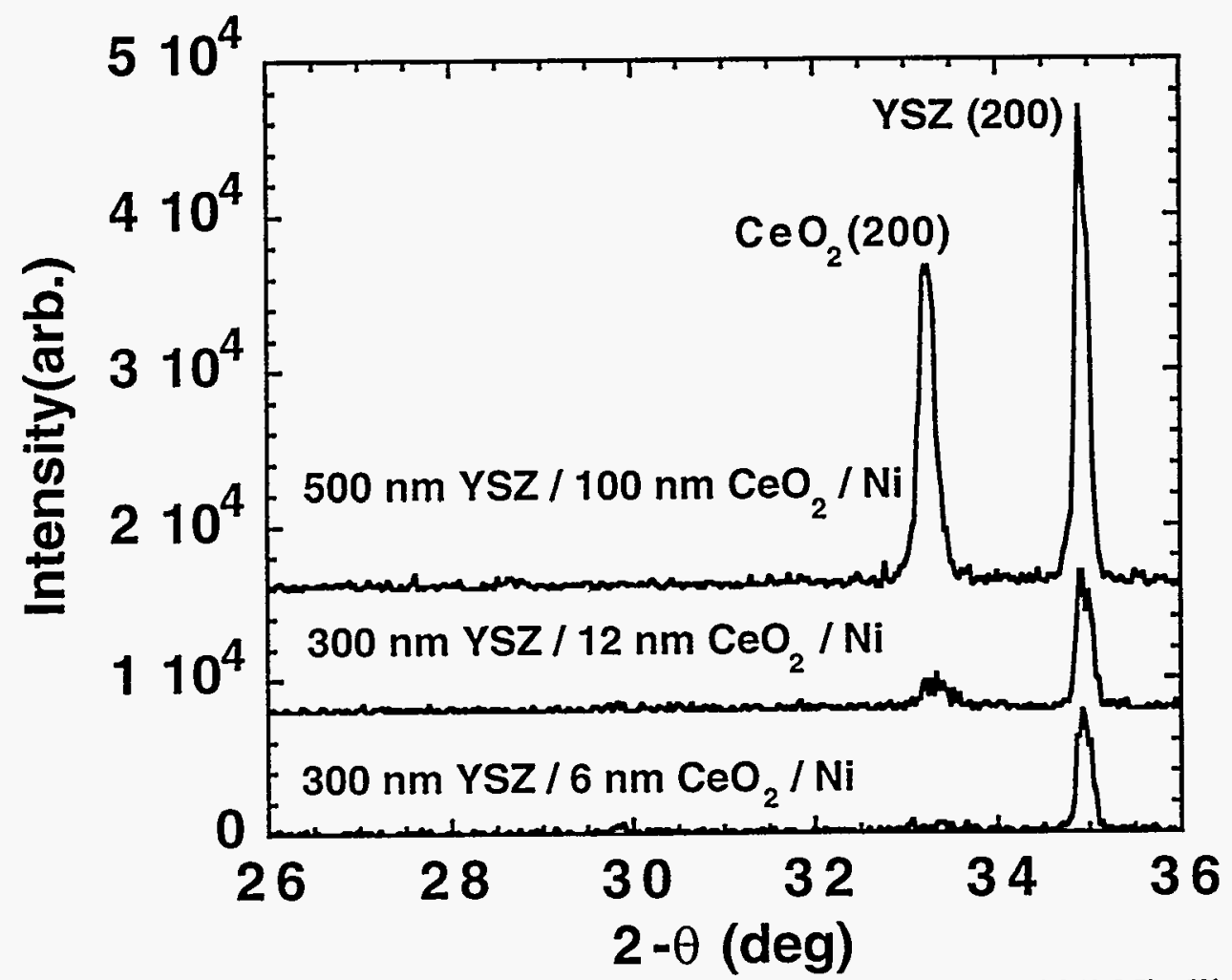

Fig. 3. X-ray diffraction patterns for $\mathrm{CeO}_{2} / \mathrm{YSZ}$ bilayers grown on (001) Ni. The initial $\mathrm{CeO}_{2}$ layer was nucleated in the presence of the $4 \% \mathrm{H}_{2} / \mathrm{Ar}$ mixture. 


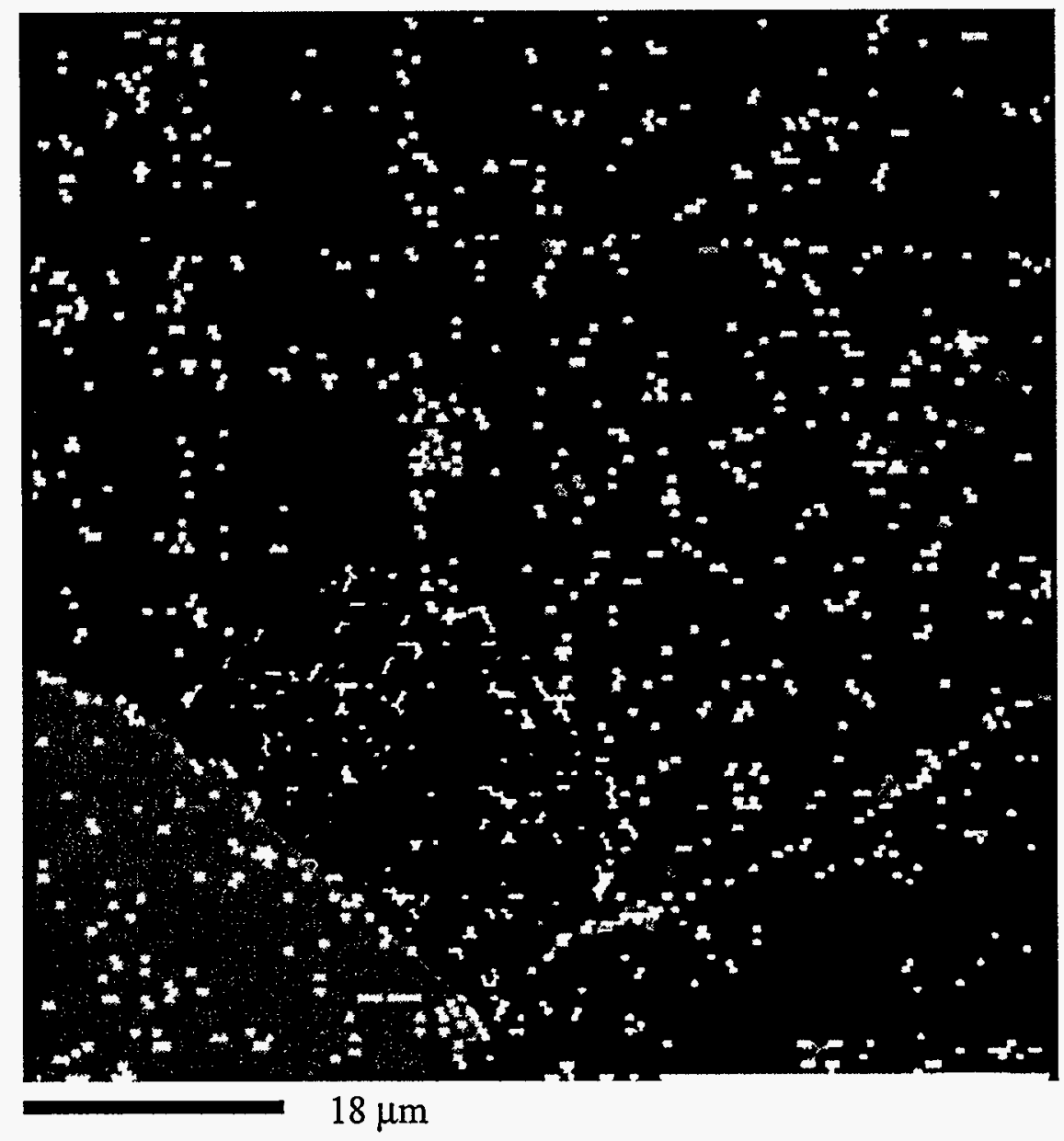

Fig. 6 Electron back-scattered pattern of a $\mathrm{CeO}_{2} / \mathrm{YSZ}$ bilayer grown on (001) Ni. The continuous shading indicates a point-to-point crystallographic change of less than $1^{\circ}$. The four distinct shaded regions represent nickel grains in the substrate. The dimensions of the image is $80 \times 80 \mu \mathrm{m}^{2}$.

the $\mathrm{CeO}_{2}$ layer in the presence of $\mathrm{H}_{2}$ results in the formation of (001) $\mathrm{CeO}_{2}$, with subsequent growth in either vacuum or a background of oxygen maintains this orientation. For all of the films represented in the figure, the total $\mathrm{CeO}_{2}$ layer thickness is $\sim 500 \mathrm{~nm}$. Note that the presence of $\mathrm{H}_{2}$ has little effect on the $\mathrm{CeO}_{2}$, as the Ce-O bond energy is relatively high.

In some cases, the growth of (001)-oriented $\mathrm{CeO}_{2}$ can be used as a nucleation layer for subsequent growth of other oxides that are difficult to grow directly on the $\mathrm{Ni}$ surface. Figure 4 illustrates the case where (001)-oriented yttria-stabilized zirconia (YSZ) is grown on (001) $\mathrm{Ni}$ with a $\mathrm{CeO}_{2}$ nucleation layer. For these multilayer structures, the thickness of the $\mathrm{CeO}_{2}$ layer that was deposited on the (001) Ni surface in the presence of the $\mathrm{H}_{2} / \mathrm{Ar}$ mixture is varied. Subsequent deposition of YSZ results in a (001) orientation 
orientation. The film growth was carried out at a substrate temperature of $750^{\circ} \mathrm{C}$, with an oxygen background pressure of $4 \times 10^{-4}$ Torr for the YSZ growth. Note that the $\mathrm{CeO}_{2}$ nucleation layer can be quite thin, with only complete surface coverage necessary for subsequent (001)-oriented YSZ growth. The degree of in-plane and out-of-plane alignment of this multilayer structure is illustrated in the electron back-scattered pattern shown in Fig. 5. The various shadings indicate regions of the YSZ layer that are aligned to within $1^{\circ}$. The four distinct regions of orientation represent four large $\mathrm{Ni}$ grains within the rolled-textured substrate. The similar shading of the YSZ film within a Ni grain shows that the YSZ is epitaxial with respect to the (001) Ni substrate due to the intermediate $\mathrm{CeO}_{2}$ nucleation layer.

\section{CONCLUSIONS}

We have investigated the epitaxial growth of $\mathrm{CeO}_{2}$ on various (001)-oriented metals using pulsed-laser deposition. The epitaxial relationships between $\mathrm{CeO}_{2}$ films and the underlying noble and oxidizing metal surfaces was addressed, along with the deposition conditions necessary to realize these structures. Clearly, the epitaxial growth of various oxide thin films on metals, along with the resulting heterostructures and interfaces, will continue to be an important area of research for oxide thin-film devices.

\section{ACKNOWLEDGMENTS}

This research was sponsored by the Oak Ridge National Laboratory, managed by Lockheed Martin Energy Research Corp., for the U.S. Department of Energy, under contract DE-AC05-96OR22464.

\section{REFERENCES}

1. D. P. Norton, A. Goyal, J. D. Budai, D. K. Christen, D. M. Kroeger, E. D. Specht, Q. He, B. Saffian, M. Paranthaman, C. E. Klabunde, D. Lee, B. C. Sales, and F. A. List, Science 274, 755 (1996).

2. J. D. Budai, R. T. Young, and B. S. Chao, Appl. Phys. Lett. 62, 1836 (1993).

3. N. N. Khoi, W. W. Smeltzer, and J. D. Embury, J. Electrochem. Soc. 122, 1495 (1975).

4. D. Dimos, P. Chaudhari, J. Mannhart, and F. K. LeGroues, Phys. Rev. Lett. 61, 1653 (1988). 